\title{
DELEUZE E A IMAGEM: UM PROBLEMA ESTÉTICO
}

\author{
Danilo Bilate ${ }^{1}$
}

Resumo: Este artigo busca investigar possíveis significaçôes da palavra "imagem”, que se depreendam dos textos de Deleuze sobre as artes, através de uma pesquisa filológica que respeita a cronologia de suas obras. Essa noção de imagem, fundamental para a Estética, aparece em seus comentários sobre Proust, o cinema, Bacon e Beckett, principalmente, seja com o uso do termo "imagem", seja com os termos "signo" e "ideia", àquele correlatos. Assim, verifica-se um vácuo na década de 70 , de modo que, se a noção de signo é estudada na década anterior, ao tratar de Proust, e a de ideia, em Diferença e repetição, o tema "imagem" é retomado nas duas décadas subsequentes com toda a intensidade, ao abordar a pintura de Bacon, o universo cinematográfico e a obra teatral e televisiva de Beckett.

PalaVras-chaVE: Imagem. Ideia. Signo. Deleuze.

\section{INTRODUÇÃo}

Etimologicamente, os termos "imagem", "signo" e "ideia" têm alguma proximidade, considerando-se a ambiguidade já fossilizada de imago como imitação, cópia, representação, de um lado, ou fenômeno, aparência, presença, de outro lado, assim como o sentido uniforme de signum como marca (bem como o grego character) e de idea como forma visível (do verbo grego idein, isto é, ver). Ora, ainda na reflexão etimológica, toda imago (nos dois sentidos) é um signum e, inversamente, todo signum é uma aparência, ambos se dispondo ao ver. Essa correlação etimológica é aceita por Deleuze, que a aperfeiçoa, quando afirma não apenas que toda imagem é um signo, mas também que os signos são tipos de imagens que reenviam a outras imagens,

1 Professor Adjunto do Departamento de Filosofia da Universidade Federal Rural do Rio de Janeiro (UFRRJ), Seropédica, RJ - Brasil. (D) https://orcid.org/0000-0002-9531-5237. E-mail: danilobilate@gmail.com

Realiza atualmente estágio de pós-doutorado na Université de Paris 1 - Panthéon-Sorbonne, com bolsa CAPES.

http://dx.doi.org/10.1590/0101-3173.2019.v42n3.09.p153

This is an open-access article distributed under the terms of the Creative Commons Attribution License. 
o que é sustentado pelo seu bergsonismo. ${ }^{2}$ Isso é confirmado, como veremos, pela coincidência da compreensão deleuziana de imagem, no início dos anos 80 - como matéria sinalética que causa um choque e, por ele, o pensamento - e a compreensão deleuziana de signo e de ideia nos anos 60 - como alguma coisa com a qual um violento encontro pode forçar o pensamento.

Para um aprofundamento da compreensáo sobre o sentido que a palavra "imagem" ganha, na obra de Deleuze, realizaremos um estudo historiográfico-filológico que leva em consideração principalmente os seus textos de Estética, respeitando a datação de suas publicaçôes, sem obediência a um suposto "método" rizomático de leitura e comentário deleuziano. ${ }^{3}$ É muito importante frisar, logo de início, portanto, que este trabalho historiográfico-filológico está fora de perspectivas sitiadas por eventuais deleuzianismos. Ele é escrito para os campos deleuzianos, sem que se queira a eles estar filiado. Aliás, no caso contrário, este texto seria flagrantemente contraditório, pois sua proposta analítica é antideleuziana.

Nesse sentido, se fazer um estudo sobre Deleuze, para alguns, consiste em usar sua filosofia, nos restringimos modestamente à primeira tarefa - e deixamos o convite ao leitor para fazer algo com o conceito de imagem, caso assim o queira. Nossa proposta, meramente investigativa, se limita a apresentar, se não um sentido dado por Deleuze ao termo "imagem" - posto tratar-se de um autor que intenta pensar a multiplicidade e as diferenças e que, por isso mesmo, recusaria muito provavelmente o uso de uma noção rígida, abstrata e geral de imagem - possíveis sentidos, no plural, que estariam associadas àquela palavra. Além disso, o extenso campo conceitual no qual se inserem os usos da palavra "imagem”, em Deleuze, provoca várias problematizaçôes outras que não nos cabem aqui, de modo que, quando dizemos se configurar como uma tarefa modesta, essa não é falsa como quando se constitui como orgulho pessoal, mas moderação e comedimento que se orgulha, sim, do que efetivamente é: contribuição analítica para aqueles que dela possam partir, a fim de se aprofundar em cruzamentos conceituais que, sem dúvida, são possíveis para os que desejam destrinchar a complexidade do pensamento deleuziano.

Para os dois textos que estudaremos da década de 60 (Proust e os signos e Diferença e repetição), levaremos em conta as noçôes de "signo" e de "ideia", não

\footnotetext{
2 Bergson afirma: "Toda imagem é interior a certas imagens e exterior a outras." (BERGSON, 1939, p. 21). 3 Sauvagnargues, que talvez se destaque entre os mais ortodoxos comentadores de Deleuze, também considera a cronologia de suas publicaçóes, embora se justifique longamente - indevidamente, portanto? - para fazê-lo. Ver, a respeito, Sauvagnargues (2005, p. 9-12).
} 
apenas porque etimologicamente são próximos daquele que é diretamente nosso objeto de investigação, a saber, a "imagem", mas porque o próprio Deleuze, como veremos, os aproxima. Apesar de textos da década de 70 - e, sobretudo, os principais, escritos com Guattari - como $O$ anti-Édipo e Mil platôs (publicado em 1980 e, portanto, maturado e escrito no final da década de 70) tratarem, no primeiro caso, da relação entre signo e desejo e, no segundo, entre regime de signos, agenciamento e enunciação, a noção de imagem, em seu sentido especificamente estético, é aí sumariamente ignorada. E isso significa dizer que "signo" aí é abordado mais propriamente do ponto de vista da filosofia da linguagem. Entretanto, apenas um ano após Mil platôs, com a publicação de Francis Bacon e a abertura da década de 80 , Deleuze introduz definitivamente uma abordagem estética de imagem em sua filosofia, nesse primeiro momento ainda com o termo "figura", mas depois, com os dois volumes de Cinema e também, já nos anos 90, com $O$ esgotado, empregando, sem retorno portanto, a palavra "imagem". Talvez essa demora em adotar com firmeza tal termo tenha se dado pela preocupação em não fazer confundir o seu uso, agora no campo da estética, com o que antes se fazia, no campo da gnosiologia, com a expressão "imagem do pensamento" (bem como seu oposto, "pensamento sem imagem") e, no campo da ontologia, com a distinção entre representação e simulacro, como duas espécies ontologicamente distintas de imagens. ${ }^{4}$

\section{4-1968: Proust E OS SIGNOS E Diferença E REPETIÇÁo}

A palavra "imagem" é bastante rara na obra escrita, em 1964, a propósito de Proust. Fora a expressão "imagem do pensamento", a qual serve de título para a conclusão de sua primeira parte - expressão que não tem nenhuma importância para a nossa reflexão, pois “imagem” significa aí apenas concepção

\footnotetext{
${ }^{4}$ Evidentemente, essa distinçâoo entre noções estética, gnosiológica e ontológica de imagem é feita por nós, como estratégia didática ou explicativa, sem referência explícita no texto de Deleuze, precisamente um autor que pouco trabalha com a separaçáo entre disciplinas filosóficas. De resto, aqui ignoraremos os dois temas (o gnosiológico e o ontológico), apesar do fato inconteste de serem ambos muito importantes para a filosofia deleuziana, porque pouco ajudam para a apresentação do problema estético da imagem, o qual é o nosso objeto. De todo modo, para mais detalhes sobre a expressão "imagem do pensamento", ver Nietzsche e a filosofia, cap. 3, p. 118 ss., a conclusão da primeira parte de Proust e os signos e, por último, Diferença e repetição, cap. 3. Sobre a distinção entre imagem e simulacro, ver Diferença e repetiçâo, p. 92-95, por exemplo, e o apêndice à Lógica do sentido, nomeado "Simulacro e filosofia antiga". Para aquele que desejar um estudo indiferenciado do termo "imagem", na obra deleuziana (a nosso ver, opção metodológica indesejável, que confunde as abordagens estética, ontológica e gnosiológica), incluindo a análise das noçôes de "imagem do pensamento" e de "simulacro", ver Carvalho (2014).
} 
ou noção de pensamento, modo de pensar, uma certa atitude filosófica ${ }^{5}$ - tal termo só aparece de modo banal, salvo em uma ocorrência muito enigmática, ao lado de "ideia" e de "essência" (DELEUZE, 1964, p. 84). ${ }^{6}$ Curiosamente, o que é essência segundo a interpretação de Deleuze, nesse mesmo ano? "A essência complica o signo e o sentido" (p. 110), ele afirma. E também: "É a essência que constitui a verdadeira unidade do signo e do sentido.” (p. 50).

Lembremos que, para Deleuze, como ele defende apenas dois anos antes de Proust, o sentido varia em função da força que se apropria do objeto. ${ }^{7}$ Com efeito, a coisa ou o objeto emite um signo (sonoro, visual, tátil etc.), mas essa emissão é completada, como força que dele se apropria, pelo "sujeito" (isto é, o corpo em relação com o objeto), sem o que o signo não existe de modo algum. Essa complementação é efetuada como relação signo-sentido:

Provavelmente o signo por si mesmo náo se reduz ao objeto; mas ele está ainda envelopado pela metade no objeto. Provavelmente o sentido por si mesmo não se reduz ao sujeito; mas ele depende pela metade do sujeito, das circunstâncias e das associaçóes subjetivas. Além do signo e do sentido, há a essência, como a razão suficiente dos dois outros termos e de sua relação. (p. 111). ${ }^{8}$

A essência é, por conseguinte, o que sustenta a relação signo-sentido. ${ }^{9}$ E Deleuze escreve misteriosamente, uma única vez, "essência" ao lado de "imagem”, como se se tratasse de sinônimos. De todo modo, se a imagem é o que constitui a unidade signo-sentido (imago como re-presentação, portanto, como

\footnotetext{
5 Ver, sobretudo, o que ele escreve com Guattari (1991, p. 39-40): "A imagem do pensamento, a imagem que ele se dá do que significa pensar, fazer uso do pensamento, se orientar no pensamento." Como avisamos na nota anterior, tal expressão também surge em Diferença e repetição, de 1968.

${ }^{6}$ Doravante, quando não indicarmos o nome do autor, tratar-se-á, evidentemente, de Gilles Deleuze. Além disso, para os próximos capítulos deste artigo, como na maior parte das vezes, as citaçóes são retiradas do mesmo livro que fornece o título de cada um deles; nesses casos nós também suprimiremos o indicativo da data de publicaçáo ou o uso de "ibidem", indicando apenas, portanto, a paginação.

7 "Um mesmo objeto, um mesmo fenômeno, muda de sentido segundo a força que dele se apropria." (1962, p. 4).

${ }^{8}$ Ver também as passagens seguintes, as quais só podem ser compreendidas, com mais ou menos clareza, em 1969, com a publicação de Diferença e repetição: "O que é uma essência, tal como ela é revelada na obra de arte? É uma diferença, a diferença última e absoluta." (1964, p. 53). "Em verdade, diferença e repetição são as duas potências da essência, inseparáveis e correlativas." (p. 63). "Dois aspectos da essência, diferença e repetição.” (p. 85).

9 Machado escreve sobre a relação signo-sentido: "A correlação signo-sentido significa que o signo é o enrolamento, o envolvimento, a implicaçấo do sentido, e o sentido é o desenrolamento, o desenvolvimento, a explicação do signo." (MACHADO, 2009, p. 197).
} 
presença e também como seu duplo) ou se ela é, exatamente a mesma coisa que o signum (imago como presença, dado imediato do objeto), o fato é que o conceito de signo, central em 1964, para Deleuze, o é também para nossa presente investigação.

Segundo o autor, o signo é o que "coloca a alma em movimento" (p. 123), por conseguinte, precisamente o que provoca o motus animi, como Agostinho o nomeava, para traduzir o grego pathos, o qual, por sua vez, como esse último nos lembra, era traduzido como perturbationes animi por Cícero e, por outros, como affectus. ${ }^{10}$ Enfim, se o signo coloca a alma em movimento, devemos concluir daí que ele é o que provoca o afeto ou - se entendermos por essa palavra não o efeito da alma movente, mas o fato mesmo de colocá-la em movimento - o próprio afeto. É assim que podemos compreender que o signo exerce sobre nós uma violência e que, ao fazê-lo, ele "constitui o objeto de um encontro." (p. 25; ver também p. 118). Em uma palavra, ele é o que resulta desse encontro entre duas instâncias, a saber, o objeto ou a coisa e o que podemos chamar - por falta de melhor solução para evitar a noção tradicional de sujeito - de corpo-sujeito.

Portanto, a coisa está lá e ela emite um signo, que não seria um signo, no entanto, sem um corpo-sujeito para apreendê-la. O "sujeito", que é corpo, é afetado pelo signo e essa afetação é chamada aqui de "violência". Após ou com essa situação, nomeada por Deleuze de "encontro", o sentido surge. O que garante a relação entre coisa, signo e sentido, o filósofo chama de "essência" (ou "imagem"?). Por conseguinte, "cada signo tem duas metades: ele designa um objeto, ele significa alguma coisa de diferente" (p. 37). Todavia, temos o mau hábito de crer que o sentido está escondido no objeto, que é preciso, pois, descobri-lo, esquecendo que ele é produzido na relação objeto-sujeito. ${ }^{11}$ E essa, como encontro, absolutamente circunstancial, pode provocar diferentes respostas subjetivas: o aprendizado, quando o corpo-sujeito interpreta ou decifra o signo ${ }^{12}$; a conquista involuntária da verdade ${ }^{13}$; ou, bem ao contrário, a nulidade do pensamento, resultante da vacuidade dos signos "mundanos". ${ }^{14}$

\footnotetext{
${ }^{10}$ Ver Agostinho. A cidade de Deus, livro IX, cap. 4.

11 "Nós pensamos que o 'objeto' ele mesmo tem o segredo do signo que ele emite. Nós nos inclinamos sobre o objeto, nós nos voltamos para o objeto para decifrar o signo." (1964, p. 37).

12 "Aprender é inicialmente considerar uma matéria, um objeto, um ser como se eles emitissem signos a serem decifrados, interpretados." (p. 10). E também: "Tudo o que nos ensina alguma coisa emite signos." (p. 11).

13 "Há sempre a violência de um signo que nos força a procurar, que nos omite a paz. A verdade não se encontra por afinidade, nem boa vontade, mas se revela por signos involuntários." (p. 24).

${ }^{14} \mathrm{O}$ signo mundano "anula o pensamento como açấo e se declara suficiente." (p. 13).
} 
Em todos os casos, a subjetividade não é mais uma entidade metafísica garantindo a priori o conhecimento, mas o efeito mesmo de uma relação com o mundo dos signos.

Não nos esqueçamos, porém, de que a citação que abriu a nossa reflexão não associou a imagem apenas ao signo e à essência, mas também à ideia. Sobre tal noção, contudo, o livro sobre Proust pouco diz e, para abordá-la, precisamos avançar quatro anos, para Diferença e repetição..$^{15}$ Estranhamente, lá a aproximação entre ideia e essência é suavizada: "Ideia não é exatamente essência." (1968, p. 242). E, então, mais claramente, ideia é diferenciada de representação: "A verdadeira diferença está em outro lugar: entre a ideia (estrutura-acontecimento-sentido) e a representação." (p. 247). Ao distingui-lo, Deleuze aproxima ideia de sentido (e de estrutura-acontecimento) ${ }^{16}$, opondo-a à representação, noção classicamente associada à de imagem. E, páginas antes, ele havia escrito:

O sentido é como a ideia [...]. A ideia, que percorre todas as faculdades, não se reduz, no entanto, ao sentido. É que, por sua vez, ela é também não-sentido; e não há nenhuma dificuldade em conciliar esse duplo aspecto pelo qual a ideia é constituída de elementos estruturais que não têm sentido por si mesmos, mas ela constitui o sentido de tudo o que ela produz. (p. 201).

Aqui, podemos observar uma confusa tentativa de sistematizaçáo vocabular - visto que, se, antes, parecíamos autorizados a associar diretamente ideia e essência, por exemplo, agora somos disso desautorizados - ou talvez possamos notar, ao contrário, uma tentativa, despreocupada com o rigor do uso dos termos, de ressaltar a distinção que realmente importa ("a verdadeira diferença está em outro lugar”): entre ideia e representação. Ou seja, segundo essa hipótese, Deleuze estaria mais preocupado do que qualquer outra coisa em opor imago como presença, signum, o que é dado ao ver (idein) e imago como re-presentação, produção intelectual de um pretenso sujeito incorpóreo, porque isolado ou neutralizado da relação originária com a presença (primeiro significado de imago). Com isso, um certo empirismo estaria sendo defendi-

\footnotetext{
${ }^{15}$ O estudo da noção de "ideia" toma corpo, em Diferença e repetição, logo após Deleuze relembrar o que acabamos de ver, isto é, que o signo, como objeto do encontro, força o pensamento e produz, por essa relação, o sentido (1968, p. 182). Das muitas páginas do referido livro dedicadas à noção de ideia, fora as citadas acima, destacamos as seguintes: 190, 220, 228, 236-237.

16 Sobre os termos em parênteses, ver toda a Lógica do sentido, onde fica ainda mais claro (mais explicitamente do que o uso dos hifens, na citação acima) sua sinonímia.
} 
do, completamente harmônico ao que se dizia em Proust sobre a violência do encontro entre corpo e signo.

O restante de Diferença e repetição sobre a noção de ideia não se oporá ao que pudemos sobre ela concluir partindo do que foi dito sobre o signo quatro anos antes. A ideia é como um afeto e/ou o que o provoca (SAUVAGNARGUES, 2009 , p. 228-231), um "complexo de sensação" (1968, p. 21) ou um "complexo ontológico" (p. 330), que "força em primeiro lugar a sensibilidade” (p. 353). Exatamente por isso é que não podemos nos restringir ao elemento visual - tão fortemente presente na raiz etimológica idein (bem como em imago e signum) e devemos, ao contrário, associar imagem, ideia e signo à essência e ao sentido. Há algo de invisível, constituído por forças estruturantes de toda e qualquer imagem (visível ou não) a ser percebido pela sensibilidade do corpo-sujeito (BOUANICHE, p. 207-215; SAUVAGNARGUES, 2009, p. 37 e p.87).

\section{1: FRANCIS BACON - LÓGICA DA SENSAÇÁO}

Apesar de menos raro que nos livros de 1964 e 1968, a palavra "imagem” é, de modo surpreendente, também pouco presente em 1981, no livro dedicado ao estudo dos quadros de Francis Bacon. Mas um outro termo, "figura", conceito central nesse último texto, pode nos fornecer pistas para nossa investigação. Do latim fingere, que tem o sentido primeiro de representar ou imaginar e o secundário de fingir ou inventar, "figura" é etimologicamente muito próximo do termo "imagem", contudo, Deleuze lhe dá o estatuto de conceito, ao considerá-lo como uma parte das imagens pintadas por Bacon: o "personagem" de seus quadros é a figura que, isolada, "torna-se uma imagem, um ícone" (1981, p. 11). ${ }^{17}$ Com efeito, é bem difícil saber se os comentários de Deleuze sobre Bacon podem ter um alcance universal e ser aplicados a todas as imagens ou mesmo a todas as pinturas. Mas, de toda forma, não podemos nos furtar a estudá-los.

O personagem isolado é, em Bacon, sempre um corpo: ele é justamente a figura, que não se resume a toda a imagem do quadro: "Não confundiremos sobretudo o material da figura com a estrutura material espacializante, que se encontra em outro lado." (p. 27). A imagem do quadro é, pois, definida pri-

\footnotetext{
${ }^{17}$ De resto, a despeito de sua significação contemporânea, o termo "ícone", segundo sua etimologia, vem do grego eikon, e significa precisamente imagem ou figura. Além disso, em $O$ esgotado, Deleuze autorizará explicitamente a relaçáo entre o termo "imagem" e o uso do termo "figura", tal como relacionado a Bacon (1992, p. 97, nota 15$)$.
} 
meiramente como o conjunto da estrutura e da figura, mas Deleuze acrescenta aí um terceiro "elemento de base", o contorno:

\begin{abstract}
A estrutura se apresenta então como um aplat [superfície de cor uniforme], mas que vai se enrolar como um cilindro em torno do contorno; o contorno se apresenta entâo como um isolante, redondo, oval, barra ou sistema de barras; e a figura é isolada no contorno, é um mundo totalmente fechado. (p. 37).
\end{abstract}

Podemos sustentar, mesmo se Deleuze não o faça, que a imagem do quadro é como uma Gestalt que engloba um fundo (a estrutura) e uma figura, com o contorno funcionando como o limite ou a fronteira que delimita a figura como tal.

Se, segundo Deleuze, "não há nada de mais importante para Bacon" senão "salvar o contorno" (p. 102) é, em consequência, para salvar a figura, porque ela é delimitada por aquele. É por isso que, para Bacon, falta alguma coisa - a tensão - na pintura abstrata: com ela, "a sensação é alcançada, mas permanece em um estado irremediavelmente confuso". Para "sair da catástrofe", é preciso "levar a sensação ao claro e ao preciso" (p. 103). Porém, o que diz Deleuze a propósito da sensação? "A sensação tem uma face voltada para o sujeito [...] e uma face voltada para o objeto [...]. Ou antes ela náo tem faces absolutamente, ela é as duas coisas indissoluvelmente.” (p. 39). Reencontramos aqui uma explicação muito parecida àquela dada em 1964, a fim de definir a essência, isto é, a unidade signo-sentido. No entanto, os quadros de Bacon não são narrativos, id est, eles não contam uma história segundo uma sequência qualquer de signos representativos e, assim, eles não podem tampouco ser classificados como "figurativos" ou "ilustrativos". Ora, a figura baconiana é justamente uma alternativa a esse tipo de sequência de signos representativos, mas ela permanece uma "forma sensível", a qual recusa a abstração completa: "Há duas maneiras de ultrapassar a figuração (isto é, ao mesmo tempo, o ilustrativo e o narrativo): ou bem com a forma abstrata, ou bem com a figura. Essa via da figura, Cézanne lhe deu um nome simples: a sensação. A figura é a forma sensível relacionada à sensação.” (p. 39).

Comunicaria a figura, como forma sensível, alguma coisa? Deleuze não usa a palavra "sentido" aqui, mas, ao ler Francis Bacon, ficamos, a todo momento, seduzidos por essa resposta. Entretanto, ele afirma que há uma linguagem na pintura, composta por signos paralinguísticos: "A linguagem analógica seria uma linguagem de relaçôes, que comporta os movimentos ex- 
pressivos, os signos paralinguísticos, os sopros e os gritos etc. [...] Pode-se mesmo perguntar-se se a pintura não foi sempre a linguagem analógica por excelência." (p. 107). Sabemos que o signo acompanha sempre um sentido e vice-versa. A imagem visual que constitui a pintura é, pois, ou bem ela mesma um signo ou uma composição de signos de onde a figura se destaca, graças ao contorno, como seu porta-voz, mesmo se não há rigorosamente nenhuma "voz" ou fala a portar.

\section{3: CINEMA 1: A IMAGEM-MOVIMENTO}

É claro, a principal obra deleuziana sobre o conceito de imagem é Cine$m a$, com seus dois volumes. De inspiração bergsoniana, ela aborda a imagem cinematográfica por dois prismas explicativos: a imagem-movimento e a imagem-tempo, as quais são, por sua vez, explicadas segundo diversas subdivisóes (imagem-percepção, imagem-afecçáo, imagem-pulsão etc.), para assim fazer a "taxonomia" ou o "ensaio de classificação das imagens e dos signos." (1983a, p. 7). ${ }^{18}$ Todavia, essa taxonomia se refere à história do cinema, e o estudo dessas subdivisóes do conceito geral de imagem está estritamente ligado às características desse gênero artístico. Assim, os detalhes da reflexão taxonômica são pouco importantes para nós, dado que nossa proposta é a de conhecer a ou as definiçôes deleuzianas sobre a imagem em geral, procurando seus elementos mínimos que estariam presentes em todo tipo de imagem. Desse modo, mesmo a distinção mais ampla entre imagem-movimento e imagem-tempo é menos crucial para nós do que para o próprio Deleuze.

Embora haja uma diferença fundamental entre os termos compositivos "movimento" e "tempo", para qualificar a imagem cinematográfica, esses dois gêneros maiores têm ao menos um traço em comum: nos dois casos, Deleuze nega a noção de imagens como "cortes instantâneos" (p. 10), estáveis, fixos, para substituir pela noção de uma imagem que é parte constitutiva da duração - seja a imagem-movimento como "corte móvel", cujo movimento é seu "dado imediato" (p. 11), seja a imagem-tempo como figuração mesma da duração. Se a duração, segundo sua significação bergsoniana, é como o todo "aberto" que "muda sem cessar" (p. 20), isto é, esse "todo de relaçôes" que não muda nunca quantitativamente, mas que sempre "se transforma ou muda de

${ }^{18} \mathrm{E}$ os signos também são subdivididos em tipos que igualmente nâo nos interessam aqui. Essa taxonomia dos signos é influenciada por Peirce, mas Deleuze opera aí torsões explícitas, como ele mesmo dirá depois: "Nós tomamos o termo 'signo' em um sentido completamente diferente do de Peirce.” (1985, p. 48). 
qualidade" (p. 21), qual é enfim o traço comum entre imagem-movimento e imagem-tempo? Eis a resposta de Deleuze:

O movimento tem, pois, duas faces, de alguma maneira. De um lado, ele é o que se passa entre objetos ou partes, de outro lado ele é o que exprime a duração ou o todo. [...] Há imagens-movimento que são cortes móveis da duração [e] há enfim imagens-tempo, isto é, imagensduração, imagens-mudança, imagens-relação, imagens-volume, além do movimento mesmo. (p. 22). ${ }^{19}$

No que nos concerne, o importante é compreender que as imagens podem dizer alguma coisa, precisamente porque elas são temporais ou não petrificadas. A imagem é "legível tanto quanto visível", escreve Deleuze (p. 24). Essa legibilidade só é talvez possível graças aos signos com os sentidos que os acompanham e "é certo que a imagem dá lugar aos signos" (p. 101-102). Contudo, como se efetiva essa legibilidade?

Segundo o bergsonismo deleuziano, a matéria que constitui o mundo ou o real não é outra coisa senão a imagem. A totalidade do existente, o mundo, é chamada por Deleuze de "plano de imanência", cujas imagens são as suas partes constitutivas: "Esse conjunto infinito de todas as imagens constitui um tipo de plano de imanência. A imagem existe em si, sobre esse plano. Esse em-si da imagem é a matéria." (p. 86). Mais do que ser fiel à teoria de Bergson, Deleuze obedece, assim, à etimologia: imago é presença. ${ }^{20} \mathrm{~A}$ matéria-imagem é percebida segundo o ponto de vista do corpo-sujeito, perspectiva parcial, porque o corpo-sujeito é incapaz de apreender a totalidade do mundo. Se "o plano de imanência é inteiro luz" (p. 88), essa luz, que é imagem-presença, só pode ser percebida de modo fragmentário como imagem-figuração, ${ }^{21}$ efetuada

\footnotetext{
${ }^{19}$ Ver também: "Assim, o movimento tem duas faces, tăo inseparáveis como o diante e o atrás, a frente e o verso: ele é a relação entre as partes e a afecçāo do tudo." (p. 32).

${ }^{20}$ É difícil não concordar com a leitura de Rancière, que vê nesse bergsonismo de Deleuze algo de paradoxal, na medida em que, em resumo, se tudo é imagem (presença), a realidade e o cinema não diferem (RANCIÈRE, 2005, sobretudo o texto “D'une image à l'autre? Deleuze et les âges du cinéma”). Do referido texto vale a leitura também para mostrar a hipotética ficção que consistiria em Deleuze diferenciar a imagem-movimento da imagem-tempo, hipótese rancieriana com a qual, aliás, concordamos.

${ }^{21}$ Esses termos compostos são nossos e não de Deleuze. Trata-se de um recurso didático para reconhecer os dois sentidos de imago, presença e re-presentação, mas com o uso da palavra "figuração" para dizer esse segundo sentido, de sorte, assim, a não nos esquecermos da crítica deleuziana à noção clássica de representação.
} 
como tal por um tipo de "enquadramento", o qual, não por acaso é uma técnica fundamental para a produção cinematográfica:

\begin{abstract}
A coisa e a percepção da coisa são uma única e mesma coisa, uma única e mesma imagem, mas relacionada a um ou a outro dos sistemas de referência. A coisa é a imagem tal como ela é em si, tal como ela se relaciona com todas as outras imagens das quais ela sofre integralmente a ação e sobre as quais ela reage imediatamente. Mas a percepção da coisa é a mesma imagem relacionada a uma outra imagem especial [o corposujeito] que a enquadra e que só retém dela uma ação parcial e só reage a ela mediatamente. (p. 93).
\end{abstract}

Além disso, a percepção-enquadramento não se efetua sem a complementação da memória, condição incontornável que faz com que a imagem-figuração seja sempre uma imagem temporal e não petrificada. Como o explica Bergson: "A memória, praticamente inseparável da percepção, intercala o passado no presente, contrai também em uma intuição única momentos múltiplos da duração." (BERGSON, 1939, p. 76). Seja como o que Deleuze nomeia de imagem-movimento, seja como imagem-tempo, há apenas uma "intuição única dos momentos múltiplos", fruto de uma "contração" sem a qual - podemos concluir - o sentido não existiria e a imagem não seria nunca "legível".

Se isso for verdade, resta, no entanto, uma dificuldade: como conceber a legibilidade de uma imagem não-cinematográfica? Os signos paralinguísticos nos quadros, a figura baconiana, por exemplo, não seriam, pois, cortes instantâneos, constitutivos de imagens fixas, sem temporalidade e, assim, sem legibilidade? Em sua obra de 1983, Deleuze só nos dá uma única resposta possível.

Com efeito, nossa percepção e nossa linguagem distinguem corpos (substantivos), qualidades (adjetivos) e ações (verbos). Mas as açôes, nesse sentido preciso, já trocaram o movimento pela ideia de um estado que persiste esperando que um outro o substitua; e o corpo trocou o movimento pela ideia de um sujeito que a executaria ou de um objeto que a sofreria, de um veículo que a carregaria, (1983a, p. 88). Para aplicá-lo à legibilidade das imagens estáticas (da pintura, da fotografia...), poderíamos concluir que o corpo-sujeito, inseparável da produção do sentido pelo encontro com os signos, está à espera de um movimento por vir, e é nesse processo que o sentido pode emergir. 


\section{5: CINEMA 2: A IMAGEM-TEMPO}

Apenas dois anos após a publicação do primeiro volume de Cinema, Deleuze acrescenta a ele um segundo, com importantes observaçóes sobre a noção estética de imagem. Se ele abordava, em 1981, signos paralinguísticos nos pintores, ele alude agora a "imagens pré-linguísticas" e de "signos présignificantes", mostrando uma certa equivalência entre signo e imagem. Da mesma forma, se, em 1983, ele falava de uma legibilidade da imagem, ele garante agora que essa legibilidade não é linguística, mas semiótica (do grego sêmeion, lembremos: signo, marca). E a violência do signo, como ele a nomeava em 1964, é agora nomeada pela palavra "choque", essa vibração ou afecção que faz com que o corpo-sujeito náo seja senhor do pensamento, porém, ao contrário, que faz com que a subjetividade seja produzida por e no meio das imagens onde ela se encontra: "O choque tem um efeito sobre o espírito, ele o força a pensar.” (1985, p. 205). Constatamos mudanças lexicais - e Deleuze, como podemos ver até aqui, não é um pensador muito atento à precisão de vocabulário - mas, aparentemente, nenhuma mudança conceitual.

A imagem é considerada como uma "matéria sinalética" que emite signos, cujo sentido espera o corpo-sujeito para ser interpretado: "É uma matéria não linguisticamente formada, ainda que ela o seja semioticamente [...] [É] uma matéria sinalética. E os signos mesmos são os traços de expressão que compóem essas imagens." (p. 49). ${ }^{22}$ Como vimos, Bergson afirma que as imagens estão sempre em relação com outras imagens, e Deleuze o confirma em outro lugar, na mesma época de Cinéma 1: "Uma imagem não está nunca sozinha. O que conta é a relação entre imagens.” (1983b, p. 75). Os signos, como traços de expressão que fazem com que as imagens "digam" alguma coisa, são, pois, imagens eles também, mas com funçôes particulares: "O signo é uma imagem que vale por uma outra imagem (seu objeto).” (1985, p. 46). O signo é uma imagem que assinala, isto é, que mostra, anuncia, designa. Enfim, o signo é "uma imagem particular que reenvia a um tipo de imagem" (p. 48). Em uma palavra, o signo é a imagem que provoca o sentido.

A "legibilidade" da imagem, o fato de que ela "diz" alguma coisa, sua expressividade, enfim, é possível, porque ela é enunciável, ela é o conteúdo

\footnotetext{
${ }^{22}$ Ver também: "O todo não é mais o logos que unifica as partes, mas a embriaguez, o pathos que as banha e que se distribui nelas. É desse ponto de vista que as imagens constituem uma massa plástica, uma matéria sinalética carregada de traços de expressão, visuais, sonoros, sincronizados ou não, zigzagues de formas, elementos de ação, gestos e silhuetas, sequências assintáxicas. É uma língua ou um pensamento primitivo ou antes um monólogo interior, um monólogo embriagado, operando por figuras, metonímias, sinédoques, metáforas, inversōes, atraçōes.” (p. 207).
} 
material ou objetivo que torna viável a interpretação pelo corpo-sujeito, que torna possível, portanto, a enunciação pela linguagem: "É uma massa plástica, uma matéria a-significante e a-sintáxica, uma matéria não linguisticamente formada, ainda que ela não seja amorfa e seja formada semioticamente, esteticamente, pragmaticamente. [...] Não é uma enunciação, não são enunciados. É um enunciável." Assim, a linguagem só é possível na relação direta com as imagens, todavia, essas podem ser pensadas como tais pela semiótica, ainda que o pensamento se apoie sobre a linguagem:

Nós queremos dizer que, quando a linguagem se apropria dessa matéria (e ela o faz necessariamente), entáo ela dá lugar a enunciados que vêm dominar ou mesmo substituir as imagens e os signos [...]. Também devemos definir, não a semiologia, mas a 'semiótica', como sistema das imagens e dos signos independentemente da linguagem em geral. [...] A linguagem só existe na sua reação a uma matéria não-linguajeira que ela transforma." (p. 44-45). ${ }^{23}$

Finalmente, Deleuze retoma o conceito de "cliché"24, que é aqui definido como a percepção ordinária que se efetua por um processo de enquadramento dado como tal pelo corpo-sujeito, em função do contexto social onde ele se insere:

Nós não percebemos a coisa ou a imagem inteira, nós percebemos dela sempre menos, nós percebemos apenas o que nós estamos interessados em perceber, ou antes o que nós temos interesse em perceber em razão de nossos interesses econômicos, de nossas crenças ideológicas, de nossas exigências psicológicas. Nós só percebemos, pois, ordinariamente, clichés. (p. 32).

Essa assertiva é perfeitamente coerente. Se, como vimos, Deleuze considera que a subjetividade se produz ou é produzida continuamente, no meio das imagens e dos signos que a rodeiam, pela ou na relação com essas imagens, ela está, por conseguinte, sob a influência constante daquele meio, classificado como social, político, ideológico ou de qualquer outra forma.

Opondo-se à definiçãa corrente de nossa civilização como sendo uma civilização da imagem, Deleuze defende que ela é, com efeito, uma civiliza-

\footnotetext{
${ }^{23}$ Aliás, um ano depois, Deleuze escreverá que a "semiótica de inspiração linguística" o perturba, pois "ela reduz a imagem a um enunciado", o que ele considera como um "passe de mágica" (1986, p. 92).

${ }^{24}$ Conceito já presente em Francis Bacon, sobretudo no capítulo 11, "La peinture, avant de peindre..."
} 
ção do clichê. De fato, os poderes dominantes fazem com que a imagem seja sempre reduzida ao clichê, confirmando um sentido já aceito pelos corpos-sujeitos, escondendo as possibilidades de interpretaçôes criativas:

De um lado, a imagem não deixa de cair no estado de clichê: porque ela se insere nos encadeamentos sensório-motores, porque ela organiza ou induz esses encadeamentos, porque nós não percebemos nunca tudo o que há na imagem, porque ela é feita para isso (para que nós não percebamos tudo, para que o clichê nos esconda a imagem...). Civilização da imagem? De fato, é uma civilização do clichê onde todos os poderes têm interesse em nos esconder as imagens, não forçosamente em nos esconder a mesma coisa, mas em nos esconder alguma coisa na imagem. De outro lado, ao mesmo tempo, a imagem tenta sem cessar de furar o clichê, de sair do clichê. Não se sabe até onde pode conduzir uma verdadeira imagem. (p. 32-33).

\section{2: O ESGOTADO}

O último texto de interesse para nossa investigação é $O$ esgotado, dedicado à obra de Beckett. Nele, o uso do termo “imagem” é definitivamente consolidado; muito do que concluímos até aqui a respeito dele é confirmado, mas, assim como ocorreu em Francis_Bacon, por ser uma obra dedicada a um único artista, permanece sempre a dúvida se o que é aí afirmado sobre a imagem pode ser generalizado para fora de seu universo singular, fundamentando um estatuto estético geral de imagem. De todo modo, prossigamos.

Deleuze fala em três línguas distintas, na obra becketiana, sendo a terceira, ou língua III, a que nos interessa, por ser "náo mais essa dos nomes ou das vozes, mas a das imagens, sonantes, colorantes” (1992, p. 72), Já aí fica claro ("sonantes"), uma vez mais, que as imagens não se restringem ao visível $\mathrm{e}$, além disso, embora possamos concordar parcialmente com a assertiva de que a imagem é como um "signo não discursivo" (SAUVAGNARQUES, 2005, p. 14), algo de discursividade pode estar nela presente: "É preciso, contudo, que a imagem pura se insira na linguagem, nos nomes e vozes" (1992, p. 73), ou, ainda: "A língua III pode, pois, reunir as palavras e as vozes às imagens." (p. 73-74). Frisamos que a discursividade "pode" estar presente, assim como Deleuze salienta que a língua III "pode" reunir palavras às imagens; mas o que importa é ressaltar que, se o objeto das artes é fazer uma imagem ${ }^{25}$, é "muito difícil fazer uma imagem pura, não marcada, nada além de uma imagem” (p.

25 "Fazer uma imagem, de tempos em tempos, a arte, a pintura, a música podem ter outro fim, mesmo se o conteúdo da imagem é bem pobre, bem medíocre?” (p. 71). 
71). Deleuze náo nos parece ser conclusivo nesse ponto, e a dúvida parece então permanecer: será mesmo possível uma imagem "pura", isto é, sem qualquer discursividade? De qualquer maneira, ele é assertivo, ao defender que a imagem - lembremos: como afeto e/ou provocadora de afeto - é algo processual, que "desfaz" a linguagem discursiva e, assim, como apelo à sensibilidade, liberta-a da memória e da razão:

É que a imagem não se define pelo sublime de seu conteúdo, mas por sua forma, isto é, por sua "tensão interna" ou pela força que ela mobiliza para fazer o vazio ou furar buracos, desfazer as ligaçóes das palavras, secar o suor das vozes, para se liberar da memória e da razão, pequena imagem alógica, amnésica, quase afásica, tanto permanecendo no vazio, tanto tremendo no aberto. A imagem náo é um objeto, mas um "processo". (p. 72).

Como processo, "a imagem dura o tempo furtivo de nosso prazer, de nosso olhar" (p. 77) e é nesse sentido que devemos entender por que Deleuze sustenta ser "dissipativa" a "energia da imagem": "A imagem acaba rápido e se dissipa, porque ela é ela mesma o meio para acabar-se. Ela capta todo o possível para fazê-lo saltar. Quando se diz 'eu fiz a imagem’ é que entâo acabou, não há mais possivel.” (p. 77-78). Embora possa parecer evidente, é preciso sublinhar que tais afirmaçôes valem, muito provavelmente, não apenas para as imagens em movimento do cinema, do teatro ou da televisão, mas também para as imagens fixas da escultura ou da pintura, por exemplo, pois a duração da imagem é medida pelo observador. De todo modo, é o seu caráter processual o que mais reforça a importância de que a imagem seja compreendida como o que provoca o afeto e/ou como o próprio afeto, no que ela se diferenciaria da representação: "É isso precisamente a imagem: não uma representação do objeto, mas um movimento no mundo do espírito." (p. 96). O termo "energia”, entấo, como o que diz a força ou a intensidade capaz de afetar a sensibilidade, o corpo - e o pensamento dele náo se separa ${ }^{26}$-, precisa ser sublinhado:

Uma imagem, tal como ela se mantém no vazio fora do espaço, mas também afastada das palavras, das histórias e das lembranças, engloba uma fantástica energia potencial que ela faz detonar se dissipando. $\mathrm{O}$ que conta na imagem não é o pobre conteúdo, mas a louca energia captada, pronta para arrebentar, que faz com que as imagens não durem nunca muito tempo. (p. 76; ver também SAUVAGNARGES, 2005, p. 73).

26 "Captura de forças e imagem solicitam o pensamento ao nível da sensação." (SAUVAGNARGUES, 2005, p. 36). 


\section{Conclusão}

O que esse levantamento filológico parece-nos mostrar, de modo mais imediato, é a confusão lexical presente nos escritos deleuzianos a respeito do tema "imagem". Os signos de Proust, não seriam eles imagens? As figuras de Bacon, não seriam elas os traços de expressão das imagens-quadros? Apesar disso, os dois volumes sobre o cinema e o estudo sobre Beckett parecem indicar uma relativa unidade, ou uma noção maleável de imagem em todos os livros que estudamos, independentemente das escolhas vocabulares de Deleuze. Em uma palavra, toda imago pode ter um sentido e é, portanto, em última instância, um signum que, a rigor, pode ou não se mostrar ao idein, ao ver, sendo, entretanto, sempre perceptível em alguma medida. Mas o sentido permanece virtual na espera de um encontro com o que chamamos de um "corpo-sujeito" para produzi-lo atualmente. E, ainda que possa parecer surpreendente, é justamente por isso que a imagem não se reduz à noção tradicional de representaçẫo, pois é a noção de encontro, então, que é crucial aí, porque a imagem é a provocação do afeto e o próprio afeto ao mesmo tempo. ${ }^{27}$

Dito isso, permitimo-nos, a título de conclusão, e muito sucintamente, elencar algumas questóes filosóficas que surgem graças à abordagem filológica aqui proposta. Não podemos ignorar a necessidade de uma reflexão futura sobre a "pedagogia da imagem" (1983a, p. 24) e mesmo sobre a "política da imagem" (1985, p. 252). Se vivemos de fato em uma civilização do clichê, sob o império dos signos mundanos, onde a falta de espírito governa, como fazer para distinguir aí a "inteligência", isto é, o corpo aberto à violência dos signos? Por que isso nos parece tão raro? Mas o que seria precisamente "isso", a "inteligência"? Consistiria ela, talvez, em adotar uma certa postura, um certo idein, um modo de "ver" aberto ao mundo? Distanciar-se dos clichês, multiplicando relaçóes entre signos, tirando daí imagens de sentidos novos, inesperados, fortuitos? Dar seu próprio corpo à brutalidade do mundo dos signos, abrir-se às imagens sem medo, procurar novas imagens? Abrir-se com curiosidade, amor e coragem, ao mundo? E para fazer nascer novos mundos - não precisaríamos de novas imagens?

\footnotetext{
${ }^{27}$ Assim, estamos de acordo que a imagem "não é uma cópia, um duplo mental, ainda menos uma representação da imaginação, ou um clichê da opinião, mas um modo da matéria, um movimento real e o efeito da arte deve ser entendido sobre esse plano estritamente positivo." (SAUVAGNARGUES, 2005, p. 35).
} 
A única resposta consiste em fornecer dados, carregar o mundo de dados, fazer circular alguma coisa, tanto quanto seja possível e o pouco que seja, de tal modo que, através desses dados novos ou renovados, surgissem e se propagassem questões menos cruéis, mais alegres, mais próximas da natureza e da vida. (1983a, p. 260-261).

BILATE, D. Deleuze and the image: an aesthetic problem. Trans/form/ação, Marília, v. 42, n. 3, p. 153-170, Jul./Set., 2019.

\begin{abstract}
AвSTRACT: The present article seeks to investigate possible meanings of the word "image" that can be deduced from Deleuze's writings on the arts, respecting the chronology of his works. The notion of image, which is fundamental to aesthetics, appears in Deleuze's comments on Proust, the cinema, Bacon, and Beckett, whether with the use of the term "image" or with the correlated terms "sign" and "idea". Thus, there is found in Deleuze's writings a vacuum in the 1970's: the notion of sign is studied in the previous decade when dealing with Proust and the notion of idea in Difference and repetition, and the theme of image is intensely taken up again in the following two decades in dealing with Bacon's painting, the cinematographic universe, and Beckett's theater and television work.
\end{abstract}

KeYwords: Image. Idea. Sign. Deleuze.

\title{
REFERÊNCIAS
}

BERGSON, H. Matière et mémoire. Paris: P.U.F, 1939/2004.

BOUANICHE, A. Gilles Deleuze, une introduction. Paris: Pocket, 2007.

CARVALHO, N. M. S. G. Filosofia e teoria da imagem em Gilles Deleuze. 2014. Tese (Doutorado em Filosofia) - Universidade de Lisboa, Lisboa, 2014.

DELEUZE, G. Nietzsche et la philosophie. Paris: P.U.F, 1962. . Proust et les signes. Paris: P.U.F., 1964. . Différence et répétition. Paris: P.U.F., 1968. . Logique du sens. Paris: Les Éditions de Minuit, 1969. . Francis Bacon - logique de la sensation. Paris: Éditions du Seuil, 1981/2002. . Cinéma 1: l'image-mouvement. Paris: Les Éditions de Minuit, 1983a. . Sur l'image-mouvement. In: Pourparlers. Paris: Les Éditions de Minuit, 1983b/1990. p.67-81. 
BILATE, D.

. Cinéma 2: l’image-temps. Paris: Les Éditions de Minuit, 1985.

. Doutes sur l'imaginaire. In: Pourparlers. Paris: Les Éditions de Minuit, 1986/1990. p.88-96.

. L'épuisé. Paris: Les Éditions de Minuit, 1992.

DELEUZE, G; GUATTARI, F. Qu'est-ce que la philosophie? Paris: Les Éditions de Minuit, 1991.

MACHADO, R. Deleuze, a arte e a filosofia. Rio de Janeiro: Zahar, 2009.

RANCIÈRE, J. La fable cinématographique. Paris: Seuil, 2001.

SAUVAGNARGUES, A. Deleuze et l'art. Paris: P.U.F., 2005.

. Deleuze: l'empirisme transcendental. Paris: P.UF., 2009.

Recebido: 10/10/2017

Aceito: 11/04/2019 